\title{
Learning Tool for Kids on Android Platform
}

\author{
Gulam, Afan Galih Salman ${ }^{*}$, Bayu Kanigord*
}

Computer Science Program, School of Computer Science, Bina Nusantara University, 11480, Indonesia

\author{
A R T I C L E I N F O \\ Article history: \\ Received: 16 June, 2020 \\ Accepted: 25 August, 2020 \\ Online: 14 September, 2020
}

Keywords:

Education

Mobile Application

\begin{abstract}
A B S T R A C T
The evolution of IT keeps growing worldwide, especially mobile technology. Today, mobile technology not only held by adults but also kids. The proportion of kids who used smartphones is increasing each year. The growing technology in mobile applications encourages developers to build educational apps to help kids learn to know alphabets, numbers, animals, and simple calculations in a fun way. This paper describes an educational "Homy Kid Lesson" as an Android-based application. The goal of this Homy Kid Lesson is helping children to know numbers, recognize letters, recognize animal names, and to perform simple calculations with an attractive interface. Research methods include data collection, design, and implementation. The development is done through the research literature, comparing it with similar apps, interviews, and questionnaires. Application design uses a storyboard. Its implementation refers to Extreme Programming (XP) model. The result is an educational application "Homy Kid Lesson" which can be a learning tool and as electronic media for learning with interest and fun concept. Contribution and novelty are increasing the ability of children to recognize letters and numbers early, increase the knowledge of animal names, introducing how to spell the letters and numbers to children also train the child's ability to simple counting and introduced the method of learning with electronic media.
\end{abstract}

\section{Introduction}

The development of information technology (IT) is more advanced and growing. It is also accompanied by the increasing needs of the community for technology and information. The information received is easily accessible from various locations, which can also be easily consumed by the community through technology. The development of multimedia technology also quickly offers a major change in the current human lifestyle [1]. Another supporting factor is the increasing use of smartphones, especially those based on Android. The Android operating system is an operating system on smartphones that are freely available for commercial or noncommercial use [2]. The Android operating system was introduced in 2008. Android continues to grow because it has advantages of open source and Android also offers many tools for building software that offers possibilities for application development [3].

Currently, the learning media for children in Android software is still limited such as learning letters, numbers, animals, and simple calculations for children. These apps usually offer only one learning material, such as an app for learning a letter or an app for learning numbers. Seeing these conditions would be better if learning mate- rials are combined and used as a medium of learning for children, to facilitate the children learn letters, numbers, animals, and simple calculation [4]. Therefore the application built under the name "Homy Kid Lesson" by providing features with music and animation to help children recognize letters, numbers, and animal names in a fun way, and also do simple calculations (addition and subtraction) of course with interesting and interactive images. The goal of this Homy Kid Lesson application to help the children to know numbers, recognize letters, recognize animal names, and to perform simple calculations. The benefits of this application increase the ability of children to recognize letters and numbers early, increasing the knowledge of animal names, introducing how to spell the letters and numbers to children also train the child's ability to simple counting and introduced the method of learning with electronic media.

\section{Methodology}

Mobile learning in pre-school education has potential benefits suggested by Mike et. al [5]. With the implementation of a systematic study, researchers wanted a positive impact on the use of mobile devices and ICT (information and communication technology) in

*Corresponding Authors:

Afan Galih Salman, J1. KH Syahdan No. 9, Kemanggisan, Jakarta Barat, DKI Jakarta, 11480, asalman@ binus.edu

*Bayu Kanigoro, Jl. KH Syahdan No. 9, Kemanggisan, Jakarta Barat, DKI Jakarta, 11480, bkanigoro@binus.edu 
kindergarten, not only of computers in the classroom but also on the technology used to assist teachers. The main concern is how to maximize the benefits of this instrument to improve the children's experience of ICT in education.

Mobile application for teaching mathematics has been proposed by Zaranis et. al [6] in kindergarten to helps students more active in learning and improve their initiative and opportunity for self-study. It shows that mobile application is very effective in increasing the motivation of kindergarten students for this is the position of kindergarten students to organize what, when, and where they learn. It becomes an easy platform for learning.

The basic functional requirements for mobile apps for children with special needs is proposed by Kraleva et. al [7]. This issue became very important in the last years because an increase in the number of children with special needs on a worldwide scale is observed and at the same time the increase in the use of mobile technologies.

Research design-based method proposed by Soykan et. al [8] developed for students and teachers in teaching concept skills to develop disabled students and to examine the process of developing software based on the infrastructure of operant conditioning theory. Their design-based research method developed for students and teachers in teaching concept skills to developmentally disabled students and to examine the process of developing software based on the infrastructure of operant conditioning theory.

Analysis of this type of application is done by analyzing similar apps that have been developed before. It gets an overview of these applications and gets additions so that apps can be made better. A comparison of these applications is shown in table 1

Table 1: Comparison with Similar Applications

\begin{tabular}{|l|l|l|l|l|}
\hline & $\begin{array}{l}\text { ABC } \\
\text { Sound } \\
\text { Apps }\end{array}$ & $\begin{array}{l}\text { Number } \\
\text { Baby } \\
\text { Flash } \\
\text { Cards } \\
\text { Apps }\end{array}$ & $\begin{array}{l}\text { Animal } \\
123 \text { Apps }\end{array}$ & $\begin{array}{l}\text { Homy } \\
\text { Kid } \\
\text { Lesson } \\
\text { Apps }\end{array}$ \\
\hline $\begin{array}{l}\text { Learn Al- } \\
\text { phabet }\end{array}$ & $\checkmark$ & $\boldsymbol{x}$ & $\boldsymbol{x}$ & $\checkmark$ \\
\hline $\begin{array}{l}\text { Learn } \\
\text { Number }\end{array}$ & $\boldsymbol{x}$ & $\boldsymbol{x}$ & $\boldsymbol{x}$ & $\checkmark$ \\
\hline $\begin{array}{l}\text { Learn Ani- } \\
\text { mals }\end{array}$ & $\boldsymbol{x}$ & $\boldsymbol{x}$ & $\checkmark$ & $\checkmark$ \\
\hline Animation & $\boldsymbol{x}$ & $\boldsymbol{x}$ & $\boldsymbol{x}$ & $\checkmark$ \\
\hline $\begin{array}{l}\text { Learn Mu- } \\
\text { sic }\end{array}$ & $\boldsymbol{x}$ & $\boldsymbol{x}$ & $\boldsymbol{x}$ & $\checkmark$ \\
\hline
\end{tabular}

The development combines three different levels for the system integration, framework, and structure of the game. On a conceptual level, a game is considered as a system (i.e. a set of interrelated elements). A game is designed by specifying certain relevant factors, taking into account the two fundamental dimensions of space and time: the space dimension overs the static configuration of gaming locations (virtual) and includes associated objects, attributes, and relationships, and its evolution over time covers the game dynamics On a technical level, the framework describes the basic architecture of the game development system which describes the system and its tools for developing the places, objects, actor roles, and scenarios of the video game. On a practical level, i.e. the structure of the game, the options offered to the players, and the multimedia representation of the game environment. The research method used in this study is shown in Figure 1

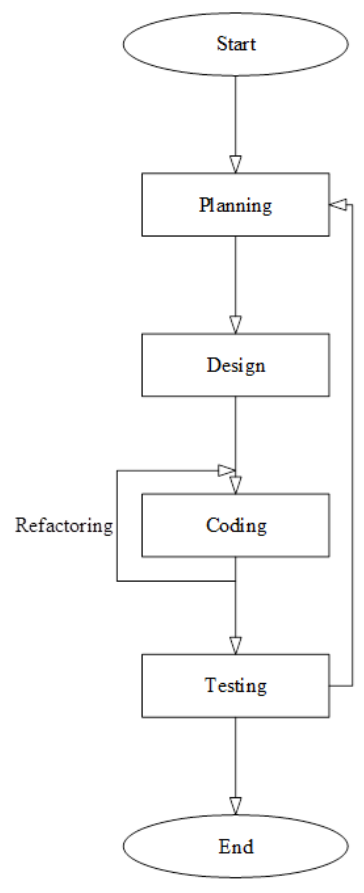

Figure 1: The research method used in this study.

The proposed app uses a model of Agile Extreme Programming (XP) [9], which has stages of development as follows: Planning, that focus to get an overview of the functions and application software through communication with the user. This phase consists of several parts: literature studies, questionnaires, interviews, and analysis of similar applications. Results of communication with the user later collected in an index of stories in which each point of the index is determined to build priorities. The design stage aims to build the pattern of the logic of a system based on a result of communication with the users. It provides a kind of design in the development of applications, namely the application design, system design using CRC maps are then formulated in UML9 also build user interface design using a storyboard. Coding, first make a unity check to test the system to be implemented and write application code on the XP model applies the concept of paired programming. Testing at this stage on XP also carried out at the coding stage is with unit tests. After each module in the unit test, the final process test this application by using Eight Golden Rules Theorem [10] as an acceptance test.

Based on the results of the questionnaire and the questionnaire obtained, several conclusions can be drawn. Most respondents agreed that the introduction of numbers, letters, and names of animals is important for young children. Most respondents agreed that early childhood children should be taught simple calculations (addition and subtraction). Some respondents answered that the method of learning while playing is very well used in providing educational insight to early childhood. Some respondents think 
that the application of education can help in providing educational insight into early childhood. Respondents on average agree that the educational applications of mobile devices can increase interest in learning in young children. The average respondent said that the age range of 3-5 years is the ideal age to provide educational insight to early childhood because in this age range the child is experiencing growth and development which is often referred to as "Golden Age". Respondents said that to increase motivation to learn in young children must be done with an attractive and attractive environment as well as a supportive environment. Respondents gave positive responses to educational applications that could help in providing educational insight into early childhood. The app will add music and animation functions to make it easier for children to recognize the letters, recognize the numbers. It will add animation to introduce the names of the animals. The survey results showed that as many as 105 respondents answered that letter recognition is important for early childhood. With so many respondents assessing the importance of this, the application will present a letter recognition feature for toddlers. As many as 105 respondents answered that the recognition of numbers is important for early childhood. With a fairly dominant number of respondents, this application will present a number recognition feature for young children. The survey results showed that as many as 105 respondents answered that the recognition of animal names is important for early childhood. With the results obtained, the application will present the name recognition feature for early childhood. The survey results showed that 77 respondents answered that early childhood should be taught simple calculations. From the viewpoint of quite a lot of respondents, the application will present a simple calculation feature for young children. Figure 2 shows the use case for the application.

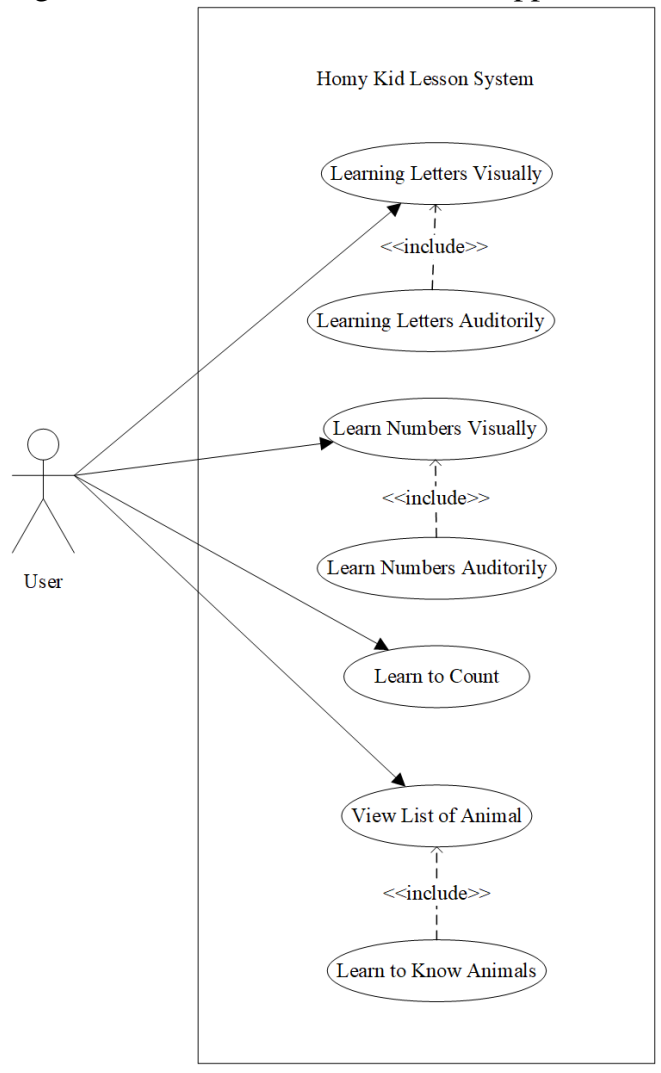

Figure 2: Use Case for "Homy Kid Lesson" app

\section{Result}

Here is the main page image of the educational app "Homy Kid Lesson". On the main page, there are four main features of the application: learn to know the letters, learn to know numbers, and learn to know the names of animals and make simple calculations, figure 3

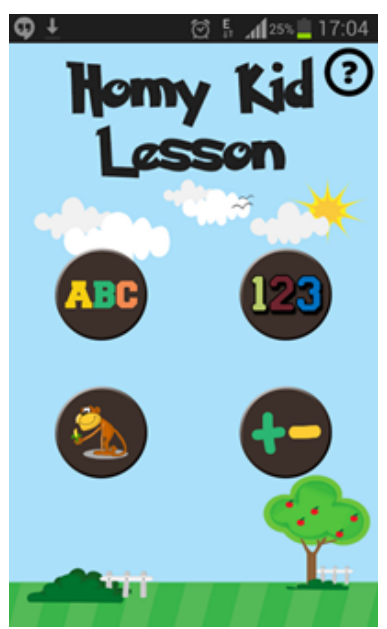

Figure 3: Home Menu

The feature screen, shown in figure 4 " $\mathrm{ABC}$ " contains alphabet letter keys from $A$ to $Z$ to learn to recognize letters. When one of the letters is selected, the page appears to learn the letter along with the spelling of the selected letter. There is also a feature to learn with music when the "music" button is pressed.
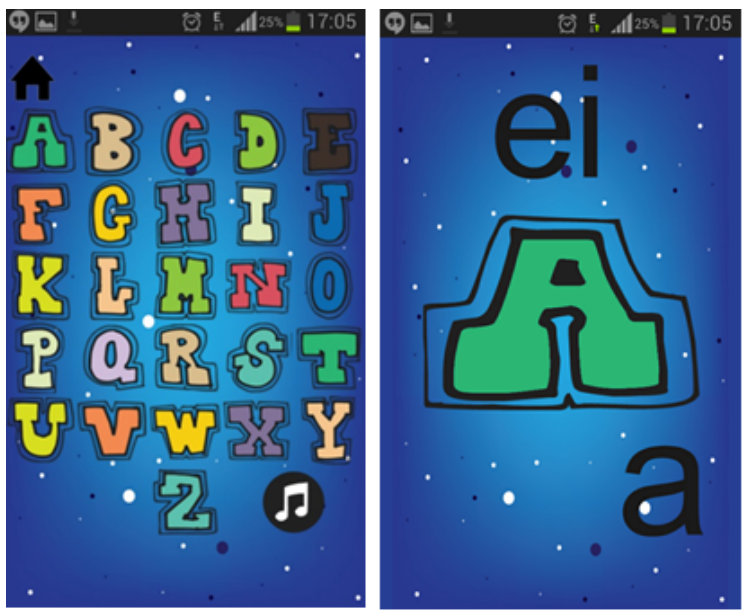

Figure 4: Learn to Know Letter

The feature screen "123", shown in figure 5, contains buttons of rows with numbers from 1 to 10 , when user pressed then will show a page to learn numbers. There is also a function to learn music when the "music" button is pressed. 

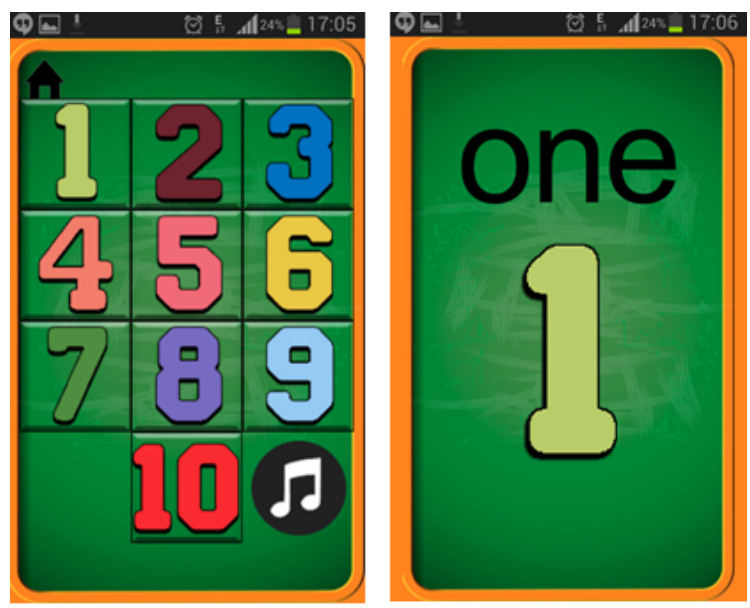

Figure 5: Learn to Know Number

The feature screen "Animals", shown in figure 6, contains a list of images of animals, when user selected one of the animals then will display the physical shape of the animal with the sound of the selected animal.

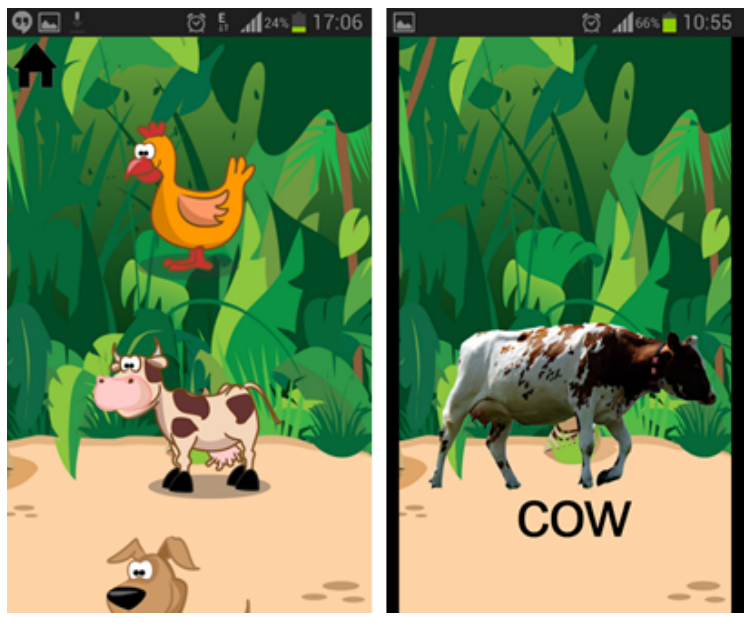

Figure 6: Learn to Know Animals

The feature screen "Count" contains two main menu plus $(+)$ and minus (-). The plus $(+)$ button is a function to perform addition mode and minus (-) functions to perform calculations in the subtraction mode. In this calculation menu, the user can try ten simple calculation questions see figure 7

Table 2 shows questionnaire results of 52 respondents that have tried "Homy Kid Lesson" application.

Table 2: Questionnaire Results

\begin{tabular}{|l|l|l|}
\hline Answer & $\begin{array}{l}\text { Number of Re- } \\
\text { spondents }\end{array}$ & Percentage \\
\hline Very Attractive & 30 & $58 \%$ \\
\hline Attractive & 22 & $42 \%$ \\
\hline Less Attractive & 0 & $0 \%$ \\
\hline Not Attractive & 0 & $0 \%$ \\
\hline
\end{tabular}

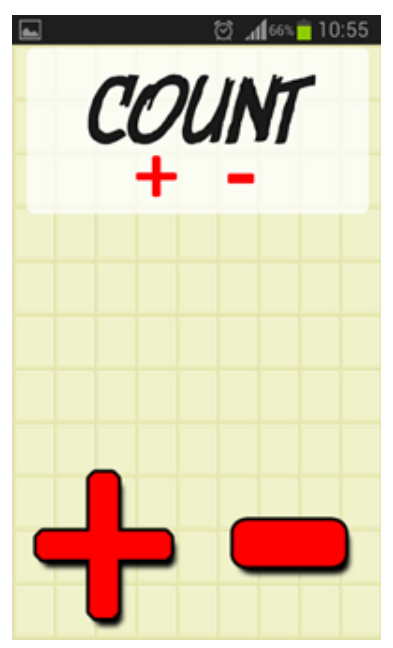

Figure 7: Learn to Know Calculation

As shown in table 2, all respondents said the educational application "Homy Kid Lesson" is very attractive to use. Application evaluation was carried out by giving questionnaires to 52 parents and teachers. They tried the educational application "Homy Kid Lesson" directly. This evaluation questionnaire includes questions relating to the eight golden rules and five measurable human factors by Shneiderman and Plaisant. Based on the evaluation results obtained, it can be concluded that the educational application "Homy Kid Lesson" is interesting in terms of appearance design, learning features, instructions, and easy to use. Overall, the educational application "Homy Kid Lesson" received a positive response so the application "Homy Kid Lesson" could be an alternative learning media for children. This app increases the ability of children to recognize letters and numbers early, increasing the knowledge of animal names, introducing how to spell the letters and numbers to children also train the child's ability to simple counting and introduced the method of learning with electronic media.

\section{Conclusion}

Educational applications "Homy Kid Lesson" can help children to learn about letters, numbers, and names of animals and to perform simple calculations. The educational application "Homy Kid Lesson" can help children learn to spell letters and words. The educational application "Homy Kid Lesson" becomes an alternative learning tool for children.

More features such as Bahasa as an add-on feature for recognizing letters and numbers. Add math material such as multiplication and division; add more objects or images for features to recognize animal names.

The contribution to this research is that this application acts as an alternative medium of learning for children. The learning method used in this application uses a fun playstyle approach.

\section{References}

[1] T. Vaughan, Multimedia: Making It Work, McGraw-Hill Osborne Media New York, 2010. 
[2] L. D. Darcey, Android Application Development in 24 Hours, Sams Publishing Indiana, 2012.

[3] M. Gargenta, Learning Android: Develop Mobile Apps Using Java and Eclipse, O'Reilly Media USA, 2011.

[4] Sutomo, Android: Pemrograman Aplikasi Mobile Smartphone dan Tablet PC berbasis Android, Informatika Bandung, 2012.

[5] M. McCabe, S. Tedesco, "Using QR codes and mobile devices to foster an inclusive learning environment for mathematics education" International Journal of Technology and Inclusive Education (IJTIE), 1(1), 37-43, (2012). https://doi.org/10.20533/ijtie.2047.0533.2012.0006

[6] N. Zaraniz, M. Kalogiannakis, S. Papadakis, "Using mobile devices for teaching realistic mathematics in kindergarten education" Creative Education, 4(7) 1, (2013). https://doi.org/10.4236/ce.2013.47a1001
[7] R. Kraleva, Velin Kralev, "An evaluation of the mobile apps for children with special education needs based on the utility function metrics" International Journal on Advanced Science Engineering and Information Technology, 8(6), 2269-2277, (2018). https://doi.org/10.18517/ijaseit.8.6.6309

[8] E. Soykan, Fezile Özdamll, "Development process of instructional mobile application for special needs children" International Journal of Technology Enhanced Learning 11,3, 259-278, (2019). https://doi.org/10.1504/ijtel.2019.10020449

[9] R. Pressman, Software engineering: a practitioner's approach, Palgrave macmillan, 2005

[10] B. Shneiderman, C. Plaisant, M. Cohen, S. Jacobs, N. Elmqvist, N. Diakopoulos, Designing the user interface: strategies for effective human-computer interaction, Pearson, 2016 